\title{
Education and Development in a Globalized Environment: The Case of Northern Nigeria
}

\author{
Yusuf, Noah
}

\begin{abstract}
The truism that education is the surest route to development in any society needs no contention. However, despite this fact, several societies in the modern world are still far from providing this basic necessity to the greater proportion of their people. This situation is considered unacceptable more so, if one considers that education has been classified as a major fundamental human rights in contemporary society. Again, in the present globalized society in which every nation is connected to the other, education is perhaps the only instrument for people to adequately cope with the new trend. In most contemporary nation-states including Nigeria, the level of educational attainment vary across regions. Such discrepancy also exist within regions and sub-regions. In Nigeria, concerns have been expressed on the glaring gap between the North and the South with regards to education. The classification of many states in the North as "EducationallyDisadvantaged-States" has not remedied the situation. This paper focuses on this important issue of the state of education in the Nigerian Northern region especially within the context of globalization. The paper suggests ways in which education can be used as a potent instrument of socio-economic, political and technological development of the region.
\end{abstract}

Key Words: Culture; Development; Education; Globalization; Inequalities; Science and Technology.

\section{Introduction}

Contemporary society has been rightly described as a global village in which there is increasing interconnection between nations, people and societies (Marsh, 1996).Even with globalization, one obvious reality 
of today's world is the disparities between and within societies in terms of development.

Education is the process of imparting and acquiring knowledge and skills about ideas, values and concepts, borne out of learning practice and experience. The latter can be imparted to or shared with others, particularly the younger generations, through formal and informal institutional arrangements, such as schools. Knowledge so acquired whether in humanities, liberal arts, science and technology are subsequently applied to sustain present and subsequent generations in their everyday life. Therefore, every human endeavour requires one form of knowledge or another. It is the proper nurturing, transmission and application of such knowledge that guarantees the development and sustenance of every society from day to day (Abiodun, 2002).

Every society must therefore generously invest in the development, building and nurturing of the minds of its youth in order to ensure that when the current generation passes on, subsequent ones are adequately equipped with requisite knowledge that will keep the society vibrant and continuously progressive.

Education is here regarded as the instrument of social change which could transform the society in significant ways. However, in order to bring this ideal into reality, educational opportunity must be made available to a large proportion of people in the society. The present situation in the Northern region with regards to education indicates a wide gap as compared with the South (Federal Ministry of Education, 2003).

The thrust of this paper is the need to take practical measures in addressing this obvious educational imbalance in the country. The rest of the paper shall be concerned with the clarification of the concepts of education, development and globalization; the theoretical perspectives; globalization, education and development in Northern Nigeria; regional disparities in education sector in Nigeria; recommendations and conclusion. 


\section{Education, Development and Globalization}

Education refers to the explicit and formalized process of learning. As an important agent of socialization, education is part of the process of learning the attitudes, values and behaviours appropriate to individuals as members of a particular culture or society (Schaefer, 1986:442). Education has taken the form of a vast and complex social institution in modern society playing fundamental roles in virtually all aspects of life of the people. For instance, it prepares citizens for the various roles demanded by other social institutions like the family, government and the economy. It also plays prominent role in transmitting culture, social control, and promoting social change.

Sociologists commonly use a wide definition of education to include not only the formalized form but also the informal learning process in the home and elsewhere (Marsh 1989:435). This obvious fact implies that education does not start and end at the doorsteps of the school. Rather, learning takes place outside formal institution - from parents, friend, mass media, in mosques and churches and even at the workplace.

Development has been defined severally by scholars. For instance, Marsh (1996:360) conceived the concept as huge changes in the lives of people and societies. These changes relate to the astronomical record of economic growth and technological breakthrough since the end of the 19th century. He further sees the concept as a progression from one condition to another. That is, from underdevelopment to development; in simple terms, of modern values, thoughts, ideas and cultural practices.

In defining development therefore, one cannot avoid concerns with social and political issues and are most focus on goals, ideals and as well as economic means. Economic development is said to have occurred when per capita income has risen and the distribution of income is improved with relative access to education, hospital, means of communication and transportation, shelter, technology of production and the quality of life in general. 
Simpson (1994) argues that the most appropriate measure of wealth and degree of development of a society is its Gross national Product (GNP). The GNP is measured in terms of the social values of the goods and services produced within the society (Marsh, 1989).

In the same direction, the United Nations Development Programme (UNDP) observed that they are rediscovering the essential truth that the people must be at the centre of all development (UNDP, 1980). The World Bank (2001) also asserts that investing in people if done right provides the finest foundation at lasting development. The Bank further noted that all people have the same basic needs in form of clean water, air, comfortable housing etc. which must be met if development is to happen. Our notion of development in this discussion would be conceived in this regard.

With regards to the concept of globalization, no acceptable definition has been reached by scholars. Wallerstein (1979) suggested that the concept is a misleading one since what is described as globalization has been happening for over 500 years. Consequently, one herculean task which scholars faced is to agree on a fairly acceptable definition of the phenomenon. Gidden's (1990) definition is seen as probably the most appropriate for an understanding of globalization as a process. He conceived the concept as reflecting a growing interdependence of world society The changes implied by this view of globalization are quite enormous suggesting the creation of a world society in which the image of a nation-state and national identity had given way to a world wide social interaction (Marsh, 1992).

While most analysts focus on the negative aspect, Gidden's conception is largely optimistic. He regards the process of globalization as having the potentials of empowering and uniting citizens as to divide them. In this way, the process is said to lead to globalization of industry and the mass media both of which allows wealth and affluence to accumulate in the hands of a few minority of global entrepreneurs. It equally has the potential of human understanding of common problems like the danger of increasing 
population growth, the scourge of HIV/Aids pandemic, pollution, and threat to the environment.

Marsh (1996) described globalization as a double-edge sword in which on one hand it brought increasing wealth and national prosperity to the highly developed capitalist countries, while on the other, is the cause of destitution and deprivation of the underdeveloped nations of the world. This definition would be seen to stand in-between the purely optimistic and pessimistic conceptions of globalization. In his popular article titled "The End of History", Fukuyama (1989) proposed that the economic and ideological struggle between communism and capitalism had ended with the latter (capitalism) emerging victorious. Globalization is therefore regarded as being a consequence of this ideological war and eventual victory of capitalism over communism. Ibrahim (2002) argued that the concept of globalization has become the biggest buzz word in contemporary social-science discourse being a broad process permeating the whole world with far reaching ramifications covering economic, political and cultural dimensions of contemporary life. Zewdie (2002) reviewed the history of globalization since the coming of the modern world economy in the 16th century Europe as one of the inherent of the world capitalist system. According to him, since this period the aspects of economic globalization have been taking place through cross border movement of goods, capital and people.

Generally then, globalization has been conceived in different ways by people. While some individuals and groups consider the phenomenon as a welcome development in the world as it portends immense benefits to humanity socially, politically, and culturally. For others, the process is an evil parcel wrapped up in deceptive and illusory ideas like the global trade, global village, free markets, enhanced world peace and other attractive acronyms. According to Fredman (2001), the current phase of globalization began in 1975 when the United States, France, Germany, Italy, Great Britain and Japan met in Paris to coordinate plans to deflate their economies. In latter years, 
Canada and Russia joined the group and became what is today known as G8.

\section{Theoretical Framework}

The most prominent theories on education are the functional and conflict paradigm. The functionalist perspective is associated with the functionalist approach to sociology. The model argues that education rationally sort and select students for further high status positions thereby meeting society's needs for talented and expert personnel. The theory further stress that one function of education in society is in terms of transmission of knowledge, bestowing status, cultural transmission, promoting social and political integration, maintaining social control and serving as agent of social, economic and technological change (Schaefer, 1989).

In contrast to the functionalist perspective, the conflict model considers education as an instrument of elite domination. That is, with education, subordinate and underprivileged groups are made to accept their inferiority and as well reinforce existing social class inequalities while discouraging alternative and moiré equitable visions of the society (Schaefer, 1989: 447). The theory further contends that educational system socializes students into values dictated by the powerful, stifle individualism and creativity in the name of maintaining order. It also argues that the level of social change promoted by education is relatively insignificant. The model also views as inhibiting, the role of education in creating standard for entry into occupations, the different ways in which status is bestowed and the existence of a dual system of private and public schools (Schaefer, 1989:447).

Conflict perspective emphasizes on the inequalities of educational opportunities and the need for social change. Classical Marxists have emphasized the role of education in perpetuating the necessary supportive ideology in capitalist society. Marx and Engels (1976:502) condemned education (in a capitalist society) as a means by which the state maintains a capitalist system an its associated inequalities. 
Other Marxist writers have further probe into the processes by which inequality is perpetuated through education. For instance, Boule and Gintis (1976) analysed the relationship between child experience in school and inequalities they encounter as adults in the workplace. The school is thus seen as introducing and reproducing inequalities of social class that are perpetuated in a capitalist system. Other NeoMarxists also focus on education as hegemony and the role of ideological superstructure in perpetuating social inequalities. In this direction, Althusser (1977) regards education as playing a vital role with the ideological state apparatus perpetuating inequalities by conditioning the masses to accept the status-quo.

The third theoretical approach is the interpretative perspective popularized by Weber (1964). The approach seeks to understand the meaning that individuals and groups attach to their behaviour. The interest here is how structural inequalities are maintained by educational process by focusing on classroom interaction (Willis, 1977:1).

For the purpose of the present discussion, the functionalist perspective shall be adopted as it is relevant in stressing on the imperative role of education for promoting sustainable development of the Nigerian Northern region.

\section{Globalization, Education and Development in Northern Nigeria}

Globalization which has rightly been described as a buzz word in the world economic development is a comprehensive process which includes production, consumption and organization of materials and non material life according to the ethos of capitalism in a unipolar world. Globalization embodies the values of efficiency, supremacy of the market and accompanying de-emphasis on welfare. Its strategies include among others, structural adjustment which emphasizes the values of efficiency, liberalization, cost recovery and commercialization and little attention to aspects like welfare. Globalization reflects the unipolar and unidollar world and the accompanying massive restructuring (Aina, 1997). 
In Nigeria, as well as elsewhere in the developing world, globalization has enormous impacts on virtually all aspects of life including education. Such impacts include low budgetary allocation to education (see table 1) visible decay or total collapse of infrastructures, discontinuation of service, commercialization of other services, policy of cost recovery and revenue generation all of which seems to be the features of educational system in contemporary Nigeria (Alubo, 1999). As reflected in table 1, educational sector has continued to attract low budgetary allocation since the recession period in the 1980s. This is evidenced at both state and federal levels. This policy no doubt is part of the overall de-emphasis on non-productive aspects of the economy. It is also apparent that existing facilities are in state of acute disrepairs through deliberate and systematic neglect. Services like catering, accommodation and transportation have also been commercialized or privatized in most educational institutions in the country. Private sector involvement in these services is obvious reality of the overall philosophy of globalization. The primacy of market influence engendered by globalization has also led to the rationalization of courses especially in the nation's higher educational institutions. For instance, programmes like Philosophy, Classics, and Civics have either been out rightly rationalized or merged in some Nigerian universities. At the same time, some other courses like Marketing, Business Management, and Computer are being expanded to justify their relevance in the globalized world dominated by economic determinism.

The impact of the globalized environment on education and development in Northern Nigeria is very profound. Against the backdrop of low educational level in the region, the existing environment brings several constraints and challenges which must be overcome in efforts to raise the educational fortune of the region thereby ushering in sustainable development.

Among the long-term objectives of the New Partnership for African Development (NEPAD) is the eradication of poverty in Africa and to put the continent both individually and collectively on a path to 
sustainable growth and development and thus halt the marginalization of Africa in the globalization process. This ideal is expected to be attained through the revitalization and extension of education and technical training (African Union, 2001). The import of this is the emphasis on education as the tool for development at the continental level. It then becomes imperative that development efforts at the national and sub-national levels must also take cognizance of the role of education.

\section{Regional Disparities in Education Sector in Nigeria}

The regional disparities in educational development and spread in Nigeria are apparently large. Also, the participation rates vary across the regions. These factors would obviously imply that the level of socio-economic development among the regions would differ since education is one of the means for development. As the tables provided below indicates, there are disparities between the regions in terms of funding which obviously is responsible for the regional educational disparities in the country. For instance, in 1999, virtually all the 11year-olds in the South-East and South-West were in school, while only 1 out of 4 of all 11-year-olds in the North-Central was in school. In the South, the 14 year-olds' rate of participation was 85 percent and 71 percent in North-Central while in the other Northern zones only about 40 percent of both 11 and 14-year-olds were in school. In addition to the lower rates of participation in the Nothern zones, entries into school were also at later age. The gross enrollment rates across the zones in 1999 were, 41.8, 117.0, 68.7, 117.5, 118.2, and 129.5 for North-West, North-Central, North-East, South-West, SouthSouth and South-East respectively (F.M.E. 2003).

Tables 1-3 below show the share of Federal Government budget to education in Nigeria between 1990 and 2002, share of selected state government educational expenditure by educational levels in 1998 and the primary and junior secondary schooling completion rates by region for selected age groups (5-19 years and 20-29 years) respectively: 
Table 1 shows that budgetary allocation to education during the period covered by the analysis (1990-2002) is abysmal low. For instance, between 1990 and 1993 the percentage budgetary allocation to educational sector was below 10 per cent of the total annual budget. However, between 1994 and 1997 there was a remarkable leap (at least over 10 percent in each year). Ridiculously though, from 2000 to 2002 the allocation slide down again below 10 percent.

A cursory look at Table 2 would reflect the disparity in terms of state government educational expenditure (in percentage) in 1998. As shown in the table, most Northern states (Borno, Kano, and Plateau) expended the bulk of their educational expenditure on secondary school. However, two Northern states, Niger and Benue expended some percentage on university education, with Benue spending about 10.4 percent of the total education expenditure on university education while Niger spent 3.8 percent. However, Southern states like Rivers, Oyo and Ekiti spread their expenditure evenly between secondary, tertiary and university education.

Lastly, in Table 3 the regional disparities in education in Nigeria among the geographical zones become quite glaring. As shown in the table, the primary and junior secondary school completion rates in 1999 indicates that except for the North- Central which has completion rates of 70 and 48 percent for Primary school and JSS respectively, the other two zones in the region namely North-West and North-East have 34 and 20 percent as well as 39 and 24 percent for Primary school and JSS completion rates respectively.

The observed pattern of budgetary allocation to education revealed that Nigerian governments (both state and Federal) did not consider education expenditure as a matter of policy priority. It becomes obvious then that the pattern of government support for education in Nigeria may not sustain the target of making education as prime source of sustainable development in the country. Again, figures from the tables above reflect the glaring gap between the Northern and the Southern zones with regards to educational development. In view of 
the relevance of education to national development as advocated by NEPAD and the National Planning Commission, it would therefore be necessary to stress the need to take measures to address the obvious imbalance in educational attainment between the Northern and Southern regions of the country.

\section{Recommendations}

The following recommendations are hereby put forward towards improving the status of education in Northern Nigeria bringing about accelerated socio-economic, political and technological development:

1. Policy of Mass Education: Both the constitution of the Federal Republic of Nigeria and the National Policy on Education emphasizes the imperative of ensuring equality of education opportunities to all Nigerians at all levels. While there is a proviso that free education should be provided "when practicable", the provision of free and compulsory education at the primary level and free education at the secondary level are incontestable minimum condition. For states in the Northern region, the provision of mass education for the people is essential. There should be no compromise to this ideal as it is the only way through which education can reach a large number of the people and bring about regional, and by extension, overall national development.

2. Egalitarian Approach to Education: Closely related to the preceding recommendation is the emphasis on equal access to educational opportunities by all groups in the society. Egalitarian approach to education would imply placing emphasis on equal access in which identifiable underprivileged groups like the poor, nomadic groups, rural dwellers, etc. are not denied education. This means that the proportion of a social group represented among those with access to education should correspond with the proportion of that group in the whole population.

In addition is the need to take practical steps towards embarking on compensatory education in which children who are seen to require 
extra resources and extra help in terms of financial capability should be assisted so as to bridge the wide inequalities in educational opportunities between the regions. Education is here seen as capable of bringing about bridge in social inequality leading to a more equitable and egalitarian society. In this direction, education could serve as an instrument of social, political and economic emancipation.

3. Attitude Change: In view of the apparent general negative attitude towards western education among a large section of the people in the region, there is the need to embark on sensitization campaign to reverse this trend. The people should be made to understand that western education is not synonymous with western religion and culture.

4. Integration Approach to Education: By this, we mean the need to formally recognize the existing Arabic/Islamic education which is dominant in the region. Rather than leaving this important sector to "malams" (Arabic teacher) it is in the larger public interest for government to take measures in integrating it with the modern educational system.

5. Increase Budgetary Allocation to Education: A major problem besetting the educational sector in Nigeria and the Northern region in particular, as clearly reflected in the tables provided in this paper, is the low funding. Education in modern world is a capital intensive industry. There could be no education without funding. To address the obvious lapses in educational sector over the years, adequate fund must be made available and must be expended appropriately.

6. Improving Girl-Child Education: The extension of educational opportunity to the girl-child has been a cornerstone of every development plan. This is in view of the role of women to the development of their community (World Bank, 1997; Amali, 2006). Education for the girl-child must necessarily be a priority in efforts to expand the educational level of the Nigerian Northern region. The 
cultural and religious constraints impeding girl-child education in the region should be addressed.

7. Scholarship Programme: Scholarship programme should also be instituted to cater for the educational need of the underprivileged and special groups. This would in no small measure help to reduce the gap of educational opportunities between the privileged and the less privileged people in the region. It would also stem the tide of turnover rate in schools and colleges as well as tertiary institutions in the region.

8. Education through Information Technology: In view of the recent and on-going development in communication and Information Technologies, it is now possible for teachers and learners to interact without face to face or physical contact. This opportunity of IT educational system should be exploited by governments in the region as to bring about the desired rapid educational development of the region. This implies that it may no longer be necessary to be physically present in classrooms to disseminate and receive knowledge. Satellite communication and internet facilities have opened a new form of modern education devoid of the huge investment in construction of classrooms and other physical structures especially at the higher levels. This idea of education-withoutclassroom can foster rapid educational expansion in the region.

9. Emphasis on Science and Technological Education. A major tool of development of any nation, society or region is science and technology. They are the pillars of the well being of every nation as well as the source of economic and social development (Abiodun, 2002).In view of the importance of this form of education to overall development, it is suggested that deliberate efforts should be made to develop science and technological education. If the Northern region must continue to be relevant in the Nigerian nation and the global community at large it must place emphasis on appropriate science and technological education which would lead to technological development of the region in particular and Nigeria in general. 


\section{Conclusion}

From the paper, we have seen the apparent gap between the North and South in Nigeria with regards to educational attainment and development. We have also observed the problems faced by educational sector both in Nigeria and the Northern region, especially that of funding and challenges of globalization. In the final analysis, the expansion of educational opportunities and the provision of qualitative and functional education should be taken as deliberate policy of regional survival by all governments in the Northern states.

\section{References}

Abiodun, A.A. (2002). "Rebuilding the Foundations of Education in Nigeria" Newsletter of the Social Science Academy of Nigeria, Vol. 5, No. 2. pp.21-31.

African Union (2001). NEPAD: The New Partnership for African Development, Abuja, October.

Aina, T. (1997) Globalization and Social Policy in Africa. Dakar: Codestria. Alubo, S.O.(1999) "Globalization and the Changing Role of University in Nigeria" Newsletter of the Social Science Council of Nigeria, Vol 2, No. 1.:11-15.

Althusser, L. (1972) "Ideology and Ideological State Apparatus" in, B. Cosin ed. Educational Structure and Society, Harmondsworth: Penguin.

Amali, E. (2006). "Marginal Groups in the Democratization of Development." In, H. Saliu et. al. (eds.) Democracy and Development in Nigeria (Vol.3) Social Issues and External Relations. Lagos: Concept Publications.

Becker, H. (1952) "Social Class Variations in the Teacher-pupil Relationship" Journal of Educational Sociology, 25 (April) 451465.

Bowles, G. and Gintis, H. (1976) Schooling in Capitalist America: Educational Reforms and the Contradictions of Economic Life, New York: Basic Books.

Federal Ministry of Education (2003) Education Sector Status Report, Steering Committee.

Fukuyama, F. (1989) ."The End of History" The National Interest, 16: 3-17. Giddens, A. (1990). The Consequences of Modernity, Cambridge: Polity. 
Ibrahim, J. (2002). "Notes on globalization and Marginalization of Africa" Codesstria Bulletin, 3 \& 4:3

Marsh, I.(1996) ed. Making Sense of Society: An Introduction to Sociology, New York: Addison Wesley Longman Limited.

Marx, K. and Engels, F. (1976) Collected Works, London: Lawrence \& Wishart.

Schaefer, R. T. (1989). Sociology, New York: McGraw-Hill Inc.

Weber, M. (1964) The Theory of Social and Economic Organizations, Oxford: Oxford Univ. Press.

Willis, P.(1977). Learning to Labour: Why Working Class Kids Get Working Class Jobs, Fanborough: Saxon House.

World Bank (1997). "Gender Strategies for Sub-Saharan Africa: An Overview." African Region, No. 6.

Zewdie, M. (2002). The Impact of Globalization on Distance Education." IER Flambeau Vol. 9 No. 2:17-27.

Table 1: Share of Federal Government Budget to Education in Nigeria (1990-2002)

\begin{tabular}{cccc} 
Year & $\begin{array}{c}\text { Fed.Govt. } \\
\text { Annual Bud } \\
\text { get (\#bn) }\end{array}$ & $\begin{array}{c}\text { Total Allocation } \\
\text { o Education(\#bn) }\end{array}$ & $\begin{array}{c}\text { Education Allocation } \\
\text { as \% (\#bn) }\end{array}$ \\
\hline & & & \\
1990 & 40.70 & 2.20 & 5.45 \\
1991 & 38.70 & 1.80 & 4.62 \\
1992 & 52.10 & 2.40 & 4.60 \\
1993 & 111.60 & 8.00 & 7.20 \\
1994 & 69.20 & 10.30 & 14.86 \\
1995 & 111.50 & 12.80 & 11.50 \\
1996 & 121.20 & 15.40 & 10.81 \\
1997 & 188.10 & 16.80 & 11.53 \\
1998 & 246.30 & 23.70 & 9.61 \\
1999 & 249.00 & 27.80 & 11.13 \\
2000 & N.A & 56.60 & 8.70 \\
2001 & N.A & 62.47 & 7.00 \\
2002 & N.A & 69.03 & 5.90 \\
\hline
\end{tabular}

Source: Education Sector Status Report, Federal Ministry of Education (2003) 
Education and Development in a Globalized Environment...

Table 2: Share of Selected State Government Educational Expenditure by Educational Levels (\%) in 1998.

\begin{tabular}{lcccr} 
State & $\begin{array}{c}\text { Primary } \\
\text { Schools }\end{array}$ & $\begin{array}{c}\text { Secondary } \\
\text { Schools }\end{array}$ & $\begin{array}{c}\text { Tertiary } \\
\text { Institutions }\end{array}$ & Unive \\
\cline { 2 - 4 } & & & & \\
Enugu (S.E) & 17.0 & 52.7 & 30.3 & 0.0 \\
Rivers (S.S) & 9.7 & 50.0 & 21.4 & 18.3 \\
Borno (N.E) & 5.0 & 69.1 & 25.8 & 0.0 \\
Kano (N.E) & 9.2 & 66.3 & 24.5 & 0.0 \\
Plateau (N.C) & 3.3 & 83.9 & 12.8 & 0.0 \\
Benue (N.C) & 11.9 & 50.2 & 13.0 & 10.4 \\
Ekiti (S.W) & 10.44 & 66.2 & 13.0 & 10.4 \\
Niger (N.W) & 13.8 & 65.8 & 16.6 & 3.8 \\
Oyo (S.W) & 23.11 & 37.6 & 27.5 & 11.8 \\
\hline Average & 11.4 & 60.3 & 20.8 & 7.4 \\
\hline Source: Fed & &
\end{tabular}

Source: Federal Ministry of Education (2003)

Table 3: Primary and Junior Secondary schooling Completion rates (1999)

\begin{tabular}{lcc} 
Region (Zone) & Primary (15-19 years) & JSS (20-29 years) \\
\hline North-West & 34 & 20 \\
Nort-Central & 70 & 48 \\
North-East & 39 & 24 \\
South-West/South-South & 91 & 63 \\
South-East & 83 & 59
\end{tabular}

Source: National population commission, 2000. 